\title{
Internal Energy Distributions of Tungsten Hexacarbonyl Ions after Neutralization-Reionization
}

\author{
Š́árka Beranová and Chrys Wesdemiotis \\ Department of Chemistry, The University of Akron, Akron, Ohio, USA
}

\begin{abstract}
The internal energy distributions $P(\epsilon)$ transferred to $W(\mathrm{CO})_{6}^{+-}$during the kiloelectronvolt collisions that occur upon neutralization-reionization (NR) have been estimated based on the relative abundances of the $W(\mathrm{CO})_{0-6}^{+\cdot}$ products present in $\mathrm{NR}$ spectra (thermochemical method). The average internal energy of the incipient $\left\{\mathrm{W}(\mathrm{CO})_{6}^{+-}\right\}^{*}$ ions arising after near thermoneutral neutralization with trimethylamine followed by reionization with $\mathrm{O}_{2}$ is $\sim 9$ $\mathrm{eV}$ for $8-\mathrm{keV}$ precursor ions and is mainly deposited during reionization. For comparison, the mean internal energy of $\left\{\mathrm{W}(\mathrm{CO})_{6}^{+}\right\}^{*}$ after electron ionization (EI) or collisionally activated dissociation (CAD) is $\sim 6 \mathrm{eV}$. Making the neutralization step endothermic slightly increases the overall excitation gained; however, a large increase in endothermicity ( $>16 \mathrm{eV}$ ) causes only a modest rise of the average internal energy $(<2 \mathrm{eV})$. The $P(\epsilon)$ curve for NR increases exponentially up to $\sim 6 \mathrm{eV}$ and levels off at higher energies, showing that the probability of imparting large internal energies $(6-17 \mathrm{eV})$ is high. In sharp contrast, the most probable excitation on CAD is $\leq 6 \mathrm{eV}$, and the probability of deposition of larger energies declines exponentially. The mean internal energies after CAD and NR decrease steadily when the kinetic energy is lowered. The structure (minima-maxima) observed in the $P(\epsilon)$ distribution for EI, which most likely originates from Franck-Condon factors, is not reproduced in the distributions for NR or high energy CAD, despite the fact that all three methods involve electronic excitation. Because of the large internal energies transferred upon NR, NR mass spectrometry could be particularly useful in the differentiation of ionic isomers with high dissociation but low isomerization thresholds. (J Am Soc Muss Spectrom 1994, 5, 1093-1101)
\end{abstract}

$\mathrm{N}$ eutralization-reionization mass spectrometry (NRMS) is a tandem mass spectrometry method that concerns the generation and study of solitary neutral species in the diluted gas phase of the mass spectrometer $[1-4]$. The neutrals are produced from mass-selected ions by charge exchange neutralization or unimolecular dissociation and subsequently are characterized by the mass spectra obtained via reionization. The charge exchange process [5] has made it possible to prepare a variety of unstable or reactive molecules [6] from the corresponding readily available cations or anions [7]. Among the elusive neutrals explored in this way are carbenes [8-10], hypervalent radicals [11-14], diradicals $[9,15]$, and molecules apt to immediate intermolecular destruction (e.g., carbonic acid [16], ethynol [17], or fluoroformic acid [18]). On the other hand, identification of the neutral fragments eliminated during unimolecular dissociation has enabled answers to persisting questions that pertain to the decomposition mechanisms of both small ions (e.g., ionized aniline [19] or methyl acetate [20-22]) as well

Address reprint requests to Dr. Chrys Wesdemiotis, Department of Chemistry, The University of Akron, Akron, Ohio 44325-3601. as larger biomolecular ions (e.g., protonated peptides [23-25] or fatty acid ions [26]).

$$
\mathrm{M}^{+}+\mathrm{N} \rightarrow \mathrm{M}+\mathrm{N}^{+}
$$

Most NRMS investigations reported so far have involved charge exchange neutralization of cations (eq 1) and employed high energy collisions with stationary targets for the production and post-ionization of the neutral(s). The internal energy of the incipient neutral (M) formed in the neutralization step is mainly determined by the reaction enthalpy $\Delta H^{\circ}$ of the electron exchange process $\Delta H^{\circ}=\mathrm{IE}(\mathrm{N})-\operatorname{RE}\left(\mathrm{M}^{+}\right)$, where $\mathrm{IE}(\mathrm{N})$ is the vertical ionization energy of the gaseous target that is oxidized and $\operatorname{RE}\left(\mathrm{M}^{+}\right)$is the vertical recombination energy of the precursor ion that is reduced [5]. Exothermic neutralization $\left(\Delta H^{\circ}<0\right)$ can produce $M$ in an excited state that lies well above the dissociation threshold $[1-3,5,11]$. On the other hand, thermoneutral $\left(\Delta H^{\circ}=0\right)$ or endothermic $\left(\Delta H^{\circ}>0\right)$ neutralization normally leads to ground state neutrals $[1-3,5,11]$. Endothermicity may decrease the efficiency of charge exchange (eq 1), but does not prevent it, because the energy deficit (less than or equal to a 
few electronvolts) can be supplied by the kinetic energy of the kiloelectronvolt precursor ion $[27,28]$.

Bound neutral species accessed by thermoneutral or endothermic neutralization still can be rovibrationally excited depending on the Franck-Condon factor of the $e^{-}$exchange process $[1-3,5]$. Several theoretical and experimental investigations have demonstrated, however, that such excitation is insufficient to cause unimolecular decay of stable, polyatomic molecules [29, 30]. In these cases, the fragments observed in the neutralization-reionization (NR) mass spectra arise from decompositions after reionization. The nature and extent of these fragmentations depend on the structure and internal energy of the neutralized-reionized precursor ion [31]. For this reason, knowledge of the range of internal energies deposited upon the neutralization-reionization sequence is of fundamental interest. In this study, the internal energy distributions $P(\epsilon)$ attained upon NR of tungsten hexacarbonyl cations are determined and compared to those that result during electron ionization (EI) of $\mathrm{W}(\mathrm{CO})_{6}$ or collisionally activated dissociation (CAD) $[32,33]$ of $\mathrm{W}(\mathrm{CO})_{6}^{+}$. Only thermoneutral and endothermic charge exchange reactions are considered to preclude dissociation of the intermediate $\mathrm{W}(\mathrm{CO})_{6}$ neutrals (vide supra) and facilitate spectral interpretation; under these conditions, the observed NR fragments originate from the recovered $W(\mathrm{CO})_{6}^{+*}$ molecular cations arising upon neutralization-reionization and can be used to assess the internal energy distributions of these W(CO) ${ }_{6}^{+\cdot}$ ions [34].

Neutralization-reionization involves two consecutive charge-changing collisions. Such charge-permutating processes between a fast moving beam and a stationary target are important in mass spectrometry because of their usefulness in the study of ion structures and in chemical analysis [33]. Internal energy distributions have been measured for several types of collisional charge permutation [35], including charge exchange of a doubly to a singly charged cation [36-39], charge stripping of a mono- to a dication [37,39], and charge reversal of an anion to a cation [40]. In all these cases, one charged particle collides with a neutral molecule. Information on neutral-neutral encounters is limited to one study [41] that examined the collision-induced dissociative ionization (CIDI) $[19,42$, 43] of acetone molecules generated by metastable decomposition of the corresponding proton-bound dimer. Here, we present first data on the $P(\epsilon)$ ranges transferred upon NR, where an ion-neutral collision is followed by a neutral-neutral collision. The effects of neutralization target and kinetic energy are also addressed.

$\mathrm{W}(\mathrm{CO})_{6}^{+\cdot}$ was chosen as the projectile primarily for two reasons: (1) This ion mainly dissociates by successive decarbonylations, cach of which requires an in creasing and known amount of critical energy [34]. The latter information, together with the relative abundances of $\mathrm{W}(\mathrm{CO})_{n}^{+\cdot}$ in the NR spectrum, permits one to estimate the internal energy distribution of the nascent
$\mathrm{W}(\mathrm{CO})_{6}^{+\cdot}$ ions that emerge upon NR. (2) The internal energy ranges of $W(\mathrm{CO})_{6}^{++}$that result during $\mathrm{EI}$ or high energy CAD have been reported [34,37] and are available for comparison with the results of this study.

\section{Experimental}

The experiments were performed with a modified VG AutoSpec tandem mass spectrometer (VG Fisons Ltd., Manchester, UK) of $\mathrm{E}_{1} \mathrm{BE}_{2}$ geometry, which has been described in detail elsewhere [44]. The instrument is equipped with three collision cells, one (Cs-1) in the field-free region after the ion source and two (Cs-2 and Cs-3) between the magnet and the second electrostatic analyzer.

Tungsten hexacarbonyl was introduced through the direct insertion probe and ionized by 70 - or $10 \mathrm{eV}$ EI. The produced ions were accelerated to $8 \mathrm{keV}$ or as stated. $W(\mathrm{CO})_{6}^{+\cdot}$ was mass-selected by $\mathrm{E}_{1} \mathrm{~B}$ (MS-1) and subjected to neutralizing collisions in Cs-2. After electrostatic removal of the remaining ions, the resulting neutral beam was reionized in $C_{5}-3$. Finally, the newly formed product ions were mass-analyzed by $E_{2}$ (MS-2) and recorded in the NR spectrum. Trimethylamine (TMA), $X_{e}$, or He was utilized for neutralization and $\mathrm{O}_{2}$ was used for reionization. CAD spectra were acquired following an analogous procedure, with target gas $\left(\mathrm{O}_{2}\right)$ in Cs-3 or in Cs-2 and Cs-3 (but without electrostatic deflection). The pressure of each gas was adjusted to $\sim 20 \%$ attenuation of the precursor ion beam, which corresponds to approximately single collision conditions [45].

The ${ }^{186} \mathrm{~W}$ isotope was used for all measurements. The energy resolution tuned in the CAD and NR experiments led to a main beam width at half height of $6 \mathrm{~V}$. The spectra shown are multiscan summations and are reproducible within $\pm 10 \%$.

At $8 \mathrm{keV}$ and with TMA in $\mathrm{Cs}-2$ and $\mathrm{O}_{2}$ in Cs-3, the fluxes of neutralized-reionized W(CO) ${ }_{6}^{+\cdot}(\mathrm{m} / \mathrm{z} 354)$ and of all NR iuns $(m / z 186-354)$ relative to the flux of the unattenuated $\mathrm{W}(\mathrm{CO})_{6}^{++}$main beam, are $2 \times 10^{-5}$ and $4 \times 10^{-3}$, respectively. Comparable NR yields (within $\pm 20 \%$ ) are obtained for $\mathrm{W}(\mathrm{CO})_{5}{ }^{\circ}$ and $\mathrm{W}(\mathrm{CO})_{4}{ }_{4}^{\prime}$. which points out that the neutralization and reionization efficiencies of these tungsten carbonyls do not depend greatly on the number of ligands.

\section{Extent of Mass Discrimination at Low Kinetic Energy}

The degree of mass discrimination in the $E_{2}$ (MS.2) scans $[33,46]$ was examined by monitoring the metastable ion (MI) spectra of fast-atom bombardment $(F \wedge B)$ generated Pro $\mathrm{H}^{+}$Trp (proton-bound dimer of proline and tryptophan [23]). This dimer decomposes by two competitive processes to yield $\mathrm{ProH}^{+}(\mathrm{m} / z$ 116) and $\mathrm{TrpH}^{+}(m / z$ 205). The mass ratio of these ions (0.57) is equal to the mass ratio of $\mathrm{W}^{+\cdot}(m / z$ 186) 
to $\mathrm{W}(\mathrm{CO})_{5}{ }^{1 *}(\mathrm{~m} / \mathrm{z} 324)$, which are the smallest and largest fragments, respectively, from $\mathrm{W}(\mathrm{CO})_{6}^{+}$.

The ratio $\left[\mathrm{ProH}^{+}\right] /\left[\mathrm{TrpH}^{+}\right]$changes by $< \pm 15 \%$ if the acceleration of Pro- $\mathrm{H}^{+}$-Trp is varied between 8.0 and $4.3 \mathrm{keV}$. At $4.3 \mathrm{keV}, \mathrm{ProH}^{+}$has a kinetic energy of $1.6 \mathrm{keV} . \mathrm{W}^{+\cdot}$ reaches this kinetic energy at $3.0-\mathrm{keV}$ acceleration. However, decreasing the acceleration of $\mathrm{W}(\mathrm{CO})_{6}^{+\cdot}$ from 8.0 to $3.0 \mathrm{keV}$ reduces $\left[\mathrm{W}^{+\cdot}\right] /\left[\mathrm{W}(\mathrm{CO})_{5}^{+\cdot}\right]$ in the CAD and NR spectra by >16 times. Clearly, this dramatic change cannot be the result of mass discrimination and must be caused by other effects (vide infra). With the instrument used [44], the transmission efficiency of tandem mass spectrometry fragments starts decreasing measurably when their kinetic energy is lowered below $\sim 1 \mathrm{keV}$.

\section{Results and Discussion}

\section{Method for Estimation of $P(\epsilon)$}

The internal energy distributions gained by the nascent tungsten hexacarbonyl cation on FI, CAD, and NR were determined based on the thermochemical method introduced by Cooks and co-workers [34, 47]. This method can derive $P(\epsilon)$ curves for precursor ions with simple dissociation characteristics such as $\mathrm{W}(\mathrm{CO})_{6}^{+}$, whose primary decomposition route proceeds by a scries of consecutive CO losses (Scheme I and Figure 1) with known critical energies (Table 1). It is presumed that these reactions have similar entropy requirements and no significant kinetic effects, that is, all $\mathrm{W}(\mathrm{CO})_{6}^{+}$ precursor ions with sufficient internal energy to decompose do so by undergoing the most endothermic reaction available to them [34]. In such a case, the internal energy of each precursor ion determines how many $\mathrm{CO}$ molecules are cleaved. For example, all $W(\mathrm{CO})_{6}^{+\cdot}$ precursor ions with energies between $\epsilon_{0}(1)$ and $\epsilon_{\mathrm{o}}(2)$ will fragment to $W(\mathrm{CO})_{5}^{+*}$. Hence, the relative abundance of $\mathrm{W}(\mathrm{CO})_{5}^{+\cdot \cdot}$ in the spectrum (EI, CAD, or NR) can be taken as a measure for the number of precursor ions with internal energies ranging from $\epsilon_{0}(1)$ to $\epsilon_{0}(2)$. The abundance of W(CO) $)_{5}^{+}$, normalized over the energy interval $\epsilon_{\mathrm{o}}(2)$ to $\epsilon_{\mathrm{o}}(1)$, gives the data point at $\left[\epsilon_{\mathrm{o}}(1)+\epsilon_{\mathrm{o}}(2)\right] / 2$. By repeating the same procedure for each fragment, an internal energy distribution curve can be constructed.

A minor group of fragments from $W(\mathrm{CO})_{6}^{+\cdot}$ has the composition $\mathrm{WC}(\mathrm{CO})_{n+}^{+}$and formally arises by rearrangement loss of $\mathrm{CO}_{2}$ followed by consecutive cleavages of $\mathrm{CO}$, that is, through the sequence $\mathrm{W}(\mathrm{CO})_{6}^{+\cdot} \rightarrow$

$$
\begin{aligned}
& \mathrm{W}(\mathrm{CO}) \\
& \downarrow \\
& \mathrm{W}(\mathrm{CO})_{h}^{+\cdot} \rightarrow \mathrm{W}(\mathrm{CO})_{5}^{+\cdot} \rightarrow \mathrm{W}(\mathrm{CO})_{4}^{+\cdot} \rightarrow \\
& \text { IE } \quad \epsilon_{0}(1) \quad \epsilon_{0}(2) \\
& \mathrm{W}(\mathrm{CO})_{3}^{+\cdot} \rightarrow \mathrm{W}(\mathrm{CO})_{2}^{+\cdot} \rightarrow \mathrm{W}(\mathrm{CO})^{+\cdot} \rightarrow \mathrm{W}^{+\cdot} \\
& \epsilon_{0}(3) \quad \epsilon_{0}(4) \quad \epsilon_{0}(5) \quad \epsilon_{0}(6)
\end{aligned}
$$

\begin{tabular}{|c|c|c|}
\hline Ion & $\mathrm{IE} / \mathrm{AE}^{\mathrm{a}}$ & $E_{0}{ }^{b}$ \\
\hline$W(\mathrm{CO})_{6}^{1}$ & 8.5 & 0.0 \\
\hline$w\left(\mathrm{CO}_{5}^{1} \cdot\right.$ & 9.7 & 1.2 \\
\hline $\mathrm{W}\left(\mathrm{CO}_{4}^{\prime}\right.$ & 11.9 & 3.4 \\
\hline $\mathrm{W}(\mathrm{CO})_{3}^{\prime-}$ & 13.7 & 5.2 \\
\hline $\mathrm{W}(\mathrm{CO})_{2}^{+-}$ & 16.0 & 7.5 \\
\hline$w(C O)^{1}$ & 18.6 & 10.1 \\
\hline$W^{\prime-}$ & 21.5 & 13.0 \\
\hline WC(CO) & $2 b . y$ & $1 / 4$ \\
\hline $\mathrm{wC}^{+\cdot}$ & 28.8 & 20.3 \\
\hline
\end{tabular}

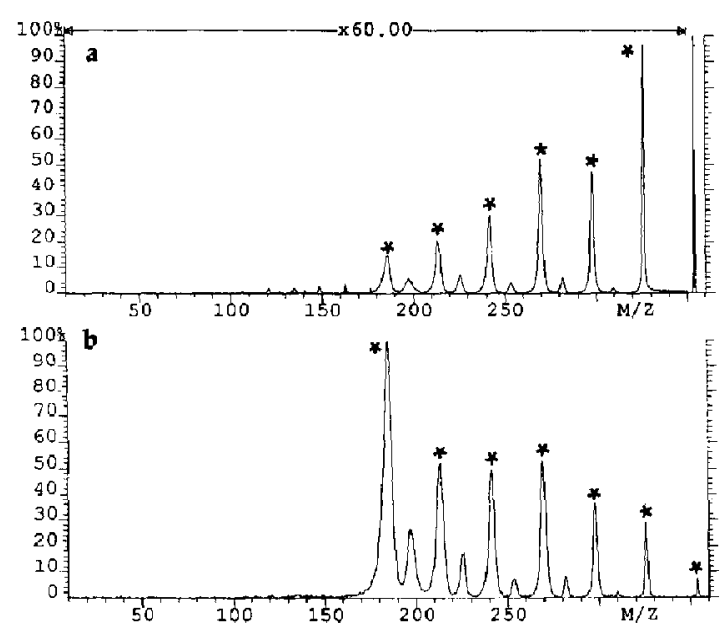

Figure 1. (a) $\mathrm{CAD}\left(\mathrm{O}_{2}\right)$ and (b) $\mathrm{NR}\left(\mathrm{TMA} / \mathrm{O}_{2}\right)$ spectra of $\mathrm{W}(\mathrm{CO})_{6}^{+*} \mathrm{~W}(\mathrm{CO})_{n}^{+\cdot}$ products are labeled by an asterisk $(*)$.

Table 1. Thermochemical data for tungsten carbonyl ions (electronvolts)

a Vertical ienization or appearance energy (IE/AE) values from refs 34 and 37 .

${ }^{b}$ Critical energies $\epsilon_{0}(n)=\mathrm{AE}(n)-\mid \mathrm{E}$.

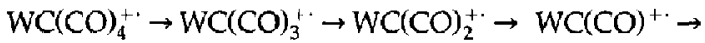
$\mathrm{WC}^{+}$. The energy requirements of the first three steps are not known. Judging from the high appearance energies for $\mathrm{WC}(\mathrm{CO})^{+\cdot}$ and $\mathrm{WC}^{+\cdot}$ (Table 1), $\mathrm{WC}(\mathrm{CO})_{n}^{+\cdot}$ type ions are high energy fragments. This conclusion is supported by the fact that the relative abundances of $\mathrm{WC} \mathrm{CO})_{n}^{+\cdot}$ in the El spectrum decrease when the ionization energy is lowered [37]. Morcover, formation of such ions requires rearrangement and may not satisfy the simple kinetic criteria of the thermochemical method [34]. For these reasons, the $\mathrm{WC}(\mathrm{CO})_{n}^{+\cdot}$ fragments were not considered in the construction of $P(\epsilon)$ curves. Also the dications present in the spectra were omitted from the derivation of $P(\epsilon)$. These cations can be used separately to determine internal energy distributions for doubly charged W(CO) ${ }_{6}^{+}+[37]$, which is not the focus of the present study.

The $P(\epsilon)$ curves obtained for FI and NR possess seven points, one for each ion shown in Scheme I. The first point is provided by $\mathrm{W}(\mathrm{CO})_{6}^{+*}$; whose abundance measures the amount of molecular ions in the internal energy range 0 to $\epsilon_{\mathrm{o}}(1)$. With $\mathrm{CAD}$, the curve starts 
with $\mathrm{W}(\mathrm{CO})_{5}^{+}$; because it is impossible to distinguish the fraction of $\mathrm{W}(\mathrm{CO})_{6}^{+*}$ that underwent activation (but no dissociation) from the fraction that did not collide at all. All curves end with the point for $W^{+} ;$it is assumed that this ion dominates in the range $\epsilon_{0}(6)$ to $\varepsilon_{\mathrm{o}}\left(\mathrm{WC}^{+\cdot}\right)[37,40,48]$. Because of the above-mentioned issues regarding the $\mathrm{WC}^{+\cdot}$ fragment, the position of the last $P(\epsilon)$ point is uncertain.

From the $P(\epsilon)$ curves, the average energies de posited are obtained by weighting the distributions, setting $P(\epsilon)=0$ for $\epsilon<\left[\epsilon_{0}(1)\right] / 2$ (in EI and NR) or $\epsilon<\left[\epsilon_{\mathrm{o}}(1)+\epsilon_{\mathrm{o}}(2)\right] / 2$ (in CAD). With all types of activation, $P(\epsilon)$ is assumed to be zero above $\left[\epsilon_{0}(6)\right.$ $\left.+\epsilon_{0}\left(W C^{+-}\right)\right] / 2$.

As a result of the simplifying assumptions made, the thermochemical method provides only approximate $P(\epsilon)$ shapes and cannot detect any fine structure. Nevertheless, it has been successfully used to appraise the internal energies deposited in a variety of collision processes, including low and high energy $\mathrm{CAD}[34,47$, 49], charge-changing reactions [37-39, 50], surface-induced dissociation [51], and angle-resolved mass spectrometry [48].

\section{Mass Spectra of $\mathrm{W}(\mathrm{CO})_{6}$}

The relative abundances of the $\mathrm{W}(\mathrm{CO})_{n}^{+\cdot}$ fragments in the acquired $\mathrm{EI}, \mathrm{CAD}$, and $\mathrm{NR}$ spectra are summarized in Tables 2 and 3. Representative complete scans of a CAD and an NR mass spectrum are displayed in Figure 1. As documented by Figure 1, the WC(CO)! series is of minor importance; its intensity, relative to the total product ion flux, is $12 \%$ in the EI $(70 \mathrm{eV}), 9 \%$ in the CAD $\left(\mathrm{O}_{2}\right)$, and $14 \%$ in the $\mathrm{NR}\left(\mathrm{TMA} / \mathrm{O}_{2}\right)$ spectra. Exclusion of such minor fragments (vide supra) is not expected to markedly affect the derived approximate internal energy distributions.

The peak widths of $W(\mathrm{CO})_{5-0}^{+-}$in the tandem mass spectra increase by $>320 \%$ from $n=5$ to $n=0$ (Figure 1), which shows that the kinetic energies released during decomposition become larger with each addi-

Table 2. W(CO) $)_{n}^{+-}$products in the EI $(70 \mathrm{eV})$ and $\mathrm{CAD}\left(\mathrm{O}_{2}\right)$ mass spectra of $W(\mathrm{CO})_{0}^{+-a}$

\begin{tabular}{|c|c|c|c|c|}
\hline \multirow[b]{2}{*}{ Ion } & \multirow[b]{2}{*}{$E I^{a}$} & \multicolumn{3}{|c|}{ CAD } \\
\hline & & $8 \mathrm{keV}$ & $5 \mathrm{keV}$ & $3 \overline{\mathrm{keV}}$ \\
\hline $\mathrm{W}(\mathrm{CO})_{6}^{+}$ & 64 & - & - & - \\
\hline$W(C O)_{5}^{+}$ & 13 & 95 & 100 & 100 \\
\hline $\mathrm{W}(\mathrm{CO})_{4}^{+\cdot}$ & 48 & 73 & 42 & 38 \\
\hline $\mathrm{W}\left(\mathrm{CO}_{3}^{+} \cdot\right.$ & 100 & 100 & 44 & 32 \\
\hline $\mathrm{W}(\mathrm{CO})_{2}^{+}$ & 60 & 67 & 31 & 19 \\
\hline$w(C O)^{+}$ & 61 & 53 & 21 & 6 \\
\hline$w^{+\cdot}$ & 55 & 50 & 8 & 2 \\
\hline
\end{tabular}

Relative abundances in percent of base peak.

hrom peak areas.

From peak heights.
Table 3. $W(\mathrm{CO})_{n}^{+\cdot}$ products in the NR mass spectra of $\mathrm{W}(\mathrm{CO})_{6}^{+\cdot a}$

\begin{tabular}{|c|c|c|c|c|c|}
\hline \multirow[b]{2}{*}{ Ion } & \multirow{2}{*}{$\begin{array}{c}\mathrm{TMA} / \mathrm{O}_{2}{ }^{\mathrm{b}} \\
8 \mathrm{keV}\end{array}$} & \multirow{2}{*}{$\begin{array}{c}\mathrm{Xe} / \mathrm{O}_{2}{ }^{\mathrm{b}} \\
8 \mathrm{keV}\end{array}$} & \multirow{2}{*}{$\begin{array}{c}\mathrm{He} / \mathrm{O}_{2}^{\mathrm{b}} \\
8 \mathrm{keV}\end{array}$} & \multicolumn{2}{|c|}{$\mathrm{TMA} / \mathrm{O}_{2}{ }^{\mathrm{b}}$} \\
\hline & & & & $5 \mathrm{keV}$ & $3 \mathrm{keV}$ \\
\hline $\mathrm{W}(\mathrm{CO})_{\mathrm{o}}^{++}$ & 2 & 0.5 & 0.2 & 8 & 11 \\
\hline $\mathrm{W}(\mathrm{CO})_{5}^{+\cdot}$ & 11 & 4 & 3 & 46 & 59 \\
\hline $\mathrm{W}\left(\mathrm{CO}_{4}^{+}\right.$ & 23 & 12 & 7 & 70 & 92 \\
\hline $\mathrm{W}\left(\mathrm{CO}_{3}^{+-}\right.$ & 38 & 25 & 15 & 95 & 100 \\
\hline $\mathrm{W}\left(\mathrm{CO}_{2}^{++}\right.$ & 41 & 29 & 20 & 100 & 67 \\
\hline $\mathrm{W}(\mathrm{CO})^{+\cdot}$ & 46 & 38 & 29 & 100 & 41 \\
\hline $\mathbf{w}^{+\cdot}$ & 100 & 100 & 100 & 85 & 33 \\
\hline
\end{tabular}

"Relative abundances in percent of base peak (from peak areas). ${ }^{b}$ In the notation $N / R, N$ and $A$ give the neutralization and reionization targets, respectively.

tional CO elimination [52]. For this reason, the $P(\epsilon)$ distributions for the tandem mass spectrometry processes (CAD and NR) were mapped by using peak areas rather than heights. The $P(\epsilon)$ curve for $C A D$ at 8 $\mathrm{keV}$ was constructed based on peak heights, too, to allow comparison with previously reported data [34, 37]. Heights also were employed for the curve derived from the EI mass spectrum of $W(\mathrm{CO})_{6}$.

Inspection of Figure 1 and Tables 2 and 3 reveals that the low mass fragments, which require more critical energy (Table 1), become more prevalent in the order CAD $\leq \mathrm{EI}<\mathrm{NR}$. This result points out that the probability to produce $\left\{\mathrm{W}(\mathrm{CO})_{6}^{+}\right\}^{*}$ with higher internal energies increases in this order. Before proceeding with the discussion of the corresponding $P(\epsilon)$ distributions, it is important to clarify the precursor of the $\mathrm{W}(\mathrm{CO})_{n}^{+\cdot}$ fragments in the NR spectra. If the $\mathrm{W}(\mathrm{CO})_{6}$ molecules accessed upon neutralization do not dissociate, all products observed after NR must arise upon reionization, that is, from excited $\mathrm{W}(\mathrm{CO})_{6}^{+\cdot}$ cations (as do all fragments in the $\mathrm{EI}$ and $\mathrm{CAD}$ experiments). Alternatively, $\mathrm{W}(\mathrm{CO})_{n}^{+\cdot}(n=0-5)$ could originate via post-ionization of $\mathrm{W}(\mathrm{CO})_{n}$, generated by dissociation of neutral $W(\mathrm{CO})_{f}$. The following arguments speak, however, against the latter pathway.

The first bond dissociation energy of neutral tungsten hexacarbonyl is $2.0 \mathrm{eV}$ [53]. Hence, spontaneous elimination of $\mathrm{CO}$ from the $\mathrm{W}(\mathrm{CO})_{6}$ molecules that emerge on neutralization could occur if the charge exchange process (eq 1) was exothermic by $\geq 2.0 \mathrm{eV}$, that is, if $\Delta H_{\mathrm{eq} 1}^{\circ}=\left[\mathrm{E}[\right.$ target $]-\mathrm{RE}\left[\mathrm{W}(\mathrm{CO})_{6}^{+\cdot}\right] \leq-\mathbf{2 . 0}$ $\mathrm{eV}$ [5]. The targets used for neutralization encompass trimethylamine (TMA), $\mathrm{X}_{\mathrm{e}}$, and He and have ionization energies (vertical for molecules) of 8.4 [54], 12.1 [55], and $24.6 \mathrm{eV}$ [55], respectively. The vertical recombination energy of $\mathrm{W}(\mathrm{CO})_{6}^{+\cdot}$ is not known, but roughly can be approximated [5] by the adiabatic ionization energy of $\mathrm{W}(\mathrm{CO})_{6}$, which is $8.2 \mathrm{eV}$ [55]. Based on these data, $\mathrm{W}(\mathrm{CO})_{6}^{+\cdot}$ neutralization is almost thermoneutral with TMA ( $\left.\Delta H_{\mathrm{eq} 1}^{\circ}=+0.2 \mathrm{eV}\right)$ and endothermic with the other two targets (by $+3.9 \mathrm{eV}$ for $\mathrm{Xe}$ and $+16.4 \mathrm{eV}$ for $\mathrm{He}$ ). Consequently, the exothermicity needed for the spontaneous decomposition of the intermediate 
$\mathrm{W}(\mathrm{CO})_{6}$ is not available. Further, the adiabatic and vertical ionization energies of $W(C O)_{6}(8.2$ and $8.5 \mathrm{cV}$, respectively) are fairly similar, which indicates that the molecular geometry does not change drastically upon electron addition. With such a favorable Franck-Condon factor, it is highly unlikely that any significant amount of $W(C O)_{6}$ is produced above its dissociation threshold during vertical neutralization $[1,3,5]$.

The possibility that the $\mathrm{W}(\mathrm{CO})_{6}^{++}$precursor contains long-lived electronically excited states also must be considered, because neutralization of such states might lead to $W(\mathrm{CO})_{6}$ molecules with sufficient energy to dissociate. The first excited electronic state of $\mathrm{W}(\mathrm{CO})_{6}^{+}$ $\left(t_{1 u}\right)$ lies $4.7 \mathrm{eV}$ above the $t_{2 g}$ ground state and requires $13.3 \mathrm{eV}$ for its formation [56]. Because this energy is larger than the appearance energies of $\mathrm{W}(\mathrm{CO})_{5}^{+\cdot}$ and $\mathrm{W}(\mathrm{CO})_{4}^{+\cdot}$ (Table 1$)$, the $t_{1 \text { u }}$ state should be short lived. The population of this state can be diminished effectively by lowering the ionization energy from 70 to $10 \mathrm{eV}$. When this is done, the CAD and NR spectra of $\mathrm{W}(\mathrm{CO})_{6}^{+\cdot}$ do not change outside experimental error, corroborating that excited states of the tungsten hexacarbonyl ion, which could form dissociating neutrals, are not present in the mass-selected beam that enters the collision cell(s).

When bound neutrals are generated in or promoted to dissociative states, they normally decompose with substantial kinetic energy release. This has becn demonstrated for $\mathrm{CH}_{4}[3,57], \mathrm{C}_{4} \mathrm{H}_{4}[58]$, and $\mathrm{CH}_{3} \mathrm{COCH}_{3}$ [27] molecules, $\mathrm{CH}_{3} \mathrm{CO}$ - radicals [59], and $\cdot \mathrm{CH}_{2} \mathrm{CH}_{2} \mathrm{OCH}_{2}$. diradicals [15], whose dissociation releases markedly more internal into translational energy than dissociation of the same bond (by an analogous mechanism) in the corresponding cations. Any dissociation of neutral $\mathrm{W}(\mathrm{CO})_{6}$ should therefore give rise, on reionization, to a much broader peak for $\mathrm{W}(\mathrm{CO})_{5}^{+\cdot}$ than dissociation of reionized or collisionally activated $W(\mathrm{CO})_{6}^{+*}$. An appreciable amount of $W(\mathrm{CO})_{5}$ in the $W(\mathrm{CO})_{6}$ beam would be detectable readily owing to the very similar reionization efficiencies of these two species (vide supra). However, the peak widths of $W(C O)_{5}^{\prime \cdot}$ in the CAD and NR spectra of ionized tungsten hexacarbonyl are comparable (22 and $24 \mathrm{~V}$, respectively, measured at half height and corrected for the precursor ion width) and the NR signal does not appear to be composite. This finding verifies that the extent of $\mathrm{W}(\mathrm{CO})_{6}^{++} \rightarrow\left\{\mathrm{W}(\mathrm{CO})_{6}\right\}^{*} \rightarrow \mathrm{W}(\mathrm{CO})_{5}+\mathrm{CO}$ is negligible.

Although the neutralizing collision does not cause any fragmentation of the intermediate $\mathrm{W}(\mathrm{CO})_{6}$, it may activate it to some degree; this aspect is discussed later. Finally, it should be kept in mind that the precursor ion-neutralization target encounter may also cause CAD instead of charge exchange. This process is most serious with $\mathrm{He}$, which exhibits poor neutralization and high CAD cross sections [27, 28]. Fortunately, $\mathrm{CAD}$ of $\mathrm{W}(\mathrm{CO})_{6}^{+\cdot}$ mainly liberates $\mathrm{CO}(28 \mathrm{u})$, which does not interfere with the $W(\mathrm{CO})_{n}^{+\cdot}$ series $(\geq m / z$ 186). $\mathrm{CO}^{+\cdot}$ is barely visible in the NR spectra (see, e.g..
Figure $1 \mathrm{~b}$ ); this is caused by the fact that $\mathrm{CO} / \mathrm{CO}^{+}$ have very low kinetic energy $(<0.7 \mathrm{keV}$ ), and thus are subject to severe scattering and transmission losses [33, 46]. Such mass discrimination effects are minimal for the $\mathrm{W}(\mathrm{CO})_{n}^{+-}$series whose mass and kinetic energy remain high due to the presence of the heavy metal tungsten (see Experimental).

\section{Internal Energy Distributions}

Electron ionization. The $P(\epsilon)$ curve of tungsten hexacarbonyl ions generated by $70-\mathrm{eV}$ EI is shown in Figure 2. It is very similar to that reported by Cooks and co-workers $[34,37]$ and reproduces all basic features of the photoelectron spectrum of $\mathrm{W}(\mathrm{CO})_{6}[56]$, which is believed to describe adequately the internal energy ranges deposited on EI [31]. Figure 2 includes a minimum at $\sim 2 \mathrm{eV}$ and a maximum at $\sim 6 \mathrm{eV}$; parallel extrema appear in the photoelectron spectrum and most probably result from differences in the electronic transition probabilities (Franck-Condon factors) at $\sim 2$ vs $\sim 6 \mathrm{eV}$. Based on Figure 2, the average internal energy of $\mathrm{W}(\mathrm{CO})_{6}^{+\cdot}$ produced by electron impact is $6 \mathrm{eV}$.

Collisionally activated dissociation. Figure 3 illustrates the internal energy distributions of collisionally activated $\mathrm{W}(\mathrm{CO})_{6}^{+\cdot}$ ions ( $8 \mathrm{keV}$ ) based on peak heights as well as peak areas. The curve shape from heights is identical within experimental error to that found by Cooks et al. [37], for $7.8-\mathrm{keV}$ precursor ions activated with $\mathrm{O}_{2}$ at $50 \%$ attenuation. The attenuation adjusted for Figure 3 is $20 \%$; there is no change if an additional

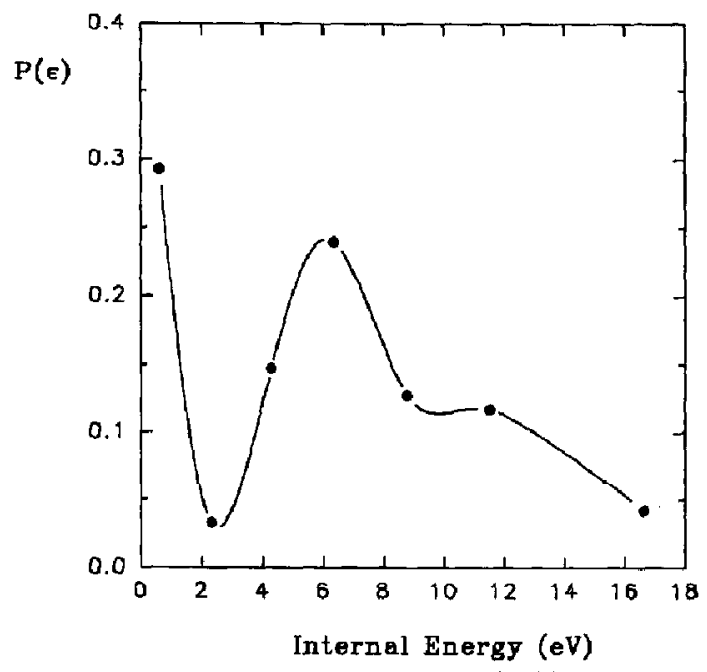

Figure 2. Internal energy distribution of $\mathrm{W}(\mathrm{CO})_{6}^{+-}$ions generated by $70-\mathrm{eV}$ EI. The data are based on peak heights. 
$20 \%$ of the main beam is attenuated by introducing collision gas into both cells located between MS-1 and MS-2 (see Experimental). Thus, within the single collision domain $[33,45]$, the $P(\epsilon)$ curve for high energy $\mathrm{CAD}$ remains insensitive to the overall target gas pressure, in agreement with previous conclusions 137,38 , 48]. The similarity between energy distributions obtained with different instruments supports the validity of the thermochemical method and substantiates the assumptions that kinetic and mass discrimination effects are negligible during the unimolecular fragmentation of ionized metal carbonyls.

With peak areas, the $P(\epsilon)$ curve for CAD shifts to higher energies and flattens below $\sim 6.5 \mathrm{eV}$ (Figure 3). Nevertheless, the overall appearance remains quite similar; both curves end with a high energy tail, which shows that there is a finite (albeit small) probability of depositing large energies. The most probable internal energies transferred lie in the range 2-6 eV and the average internal energy after CAD is $<6 \mathrm{eV}$. [Only an upper limit can be given because the molecular ion, which represents the population of lowest internal energies, is not included in the $P(\epsilon)$ curve for CAD.]

The lifetime of the $\mathrm{W}(\mathrm{CO})_{6}^{+\cdot}$ ions that reach the collision region is $26 \mu \mathrm{s}$. The metastable ion (MI) spectrum of such long-lived ions contains a small $\mathrm{W}(\mathrm{CO})_{5}^{+\cdot}$ fragment, with $\left[\mathrm{W}(\mathrm{CO})_{5}^{+\cdot}\right] /\left[\mathrm{W}(\mathrm{CO})_{6}^{++}\right] \leq$ $10^{-3}$. After CAD (Figure 1a), the fragmentation yield $\Sigma\left[\right.$ fragments $\left.{ }^{+\cdot}\right] /\left[W(\mathrm{CO})_{6}^{+\cdot}\right]$ rises dramatically to 0.5 . The miniscule extent of spontaneous MI dissociation attests that few $\mathrm{W}(\mathrm{CO})_{6}^{+\cdot}$ precursor ions possess the minimum internal energy needed for loss of one $\mathrm{CO}$ (1.2 eV; see Table 1). Evidently, the majority of the precursor ions have no excitation, and the internal

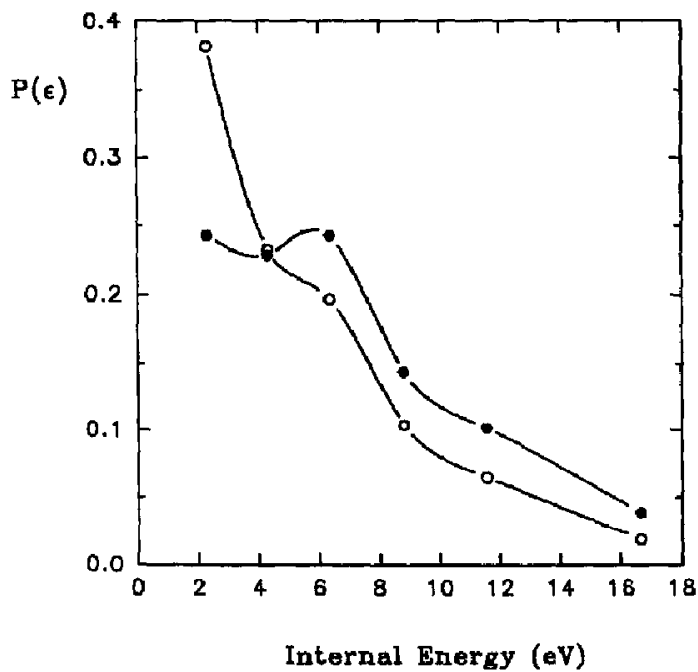

Figure 3. Internal energy distributions of $\mathrm{W}(\mathrm{CO})_{5}^{+\cdot}$ ions after $\mathrm{CAD}$ with $\mathrm{O}_{2}$ at $8 \mathrm{keV}$, based on peak heights $(O)$ and peak areas (O). energies found after CAD essentially result from the collision process.

$$
\begin{array}{r}
\mathrm{W}(\mathrm{CO})_{6}^{+\cdot}+\mathrm{N} \rightarrow \mathrm{W}(\mathrm{CO})_{6}+\mathrm{N}^{+\cdot} \\
(\mathrm{N}=\mathrm{TMA}, \mathrm{Xe}, \mathrm{He}) \\
\mathrm{W}(\mathrm{CO})_{6}+\mathrm{O}_{2} \rightarrow \mathrm{W}(\mathrm{CO})_{6}^{++}+\mathrm{O}_{2}^{-\cdot} \\
\left(\mathrm{or} \mathrm{O}_{2}+\mathrm{e}^{-}\right)
\end{array}
$$

Neutralization-reionization. The two sequential reactions that take place upon NR of ionized tungsten hexacarbonyl are described in eqs 2 and 3 . The thermochemical method provides the $P(\epsilon)$ distribution of the nascent $W(\mathrm{CO})_{6}^{+\cdot}$ ions generated in eq 3. Initially, the energy gained through both steps is considered. The more more difficult task of estimating the energy amounts transferred on each collision will be discussed later.

Neutralization of $8-\mathrm{keV} \mathrm{W}(\mathrm{CO})_{6}^{+\cdot}$ with TMA (near thermoneutral), followed by reionization with $\mathrm{O}_{2}$, leads to an internal pnergy distribution that is dramatically different from the distribution obtained for CAD (Figure 4 vs. 3). Now, $P(\epsilon)$ rises exponentially until $6 \mathrm{eV}$, before it levels off. The average internal energy of neutralized-reionized $W(\mathrm{CO})_{6}^{+}$is $9 \mathrm{eV}$ vis à vis $<6$ $\mathrm{eV}$ for collisionally activated $\mathrm{W}(\mathrm{CO})_{6}^{+\cdot}$ ions. Thus, deposition of large internal energies on $\mathrm{NR}$ is a very probable process; the reverse is true for plain collisional activation where the transfer of smaller internal energies is preferred.

The heavier weight of high internal energies in the $P(\epsilon)$ curve for neutralization-reionization explains why precursors with $\mathrm{H}$ atoms yield much more unsaturated fragments during NR than during $\mathrm{CAD}$ or $\mathrm{EI}$ [1-3]. Unsaturated fragments generally demand more critical energy than more saturated analugs [55]; consequently, they are favored in NR experiments, which more readily can supply the needed excitation.

Effect of neutralization target. Making the neutralization collision more endothermic by replacing TMA with either Xe or He does not alter significantly the NR spectra (Table 3 ) or the $P(\epsilon)$ distributions constructed from them (Figure 4). This result justifies the widely accepted opinion $[1-5,27,28]$ that endothermic neutralization produces the intermediate neutral in the same electronic state as a thermoneutral ("resonant" [5]) reaction.

The $P(\epsilon)$ shapes are not completely independent of the neutralization target (Figure 4). Increasing the endothermicity moves the curves toward higher internal energies. As a consequence, the average internal energy of the incipient neutralized-reionized $\mathrm{W}(\mathrm{CO})_{6}^{+}$. changes from $9 \mathrm{eV}$ for TMA to $10 \mathrm{eV}$ for $X \mathrm{e}$ and $11 \mathrm{eV}$ for He. Note, however, that a strong change in $\Delta H_{\text {eq2 }}^{\circ}$ (by $+3.7 \mathrm{eV}$ from TMA to $X e$ and another $+12.5 \mathrm{eV}$ from $\mathrm{Xe}$ to $\mathrm{He}$ ) is accompanied by a relatively subtle 


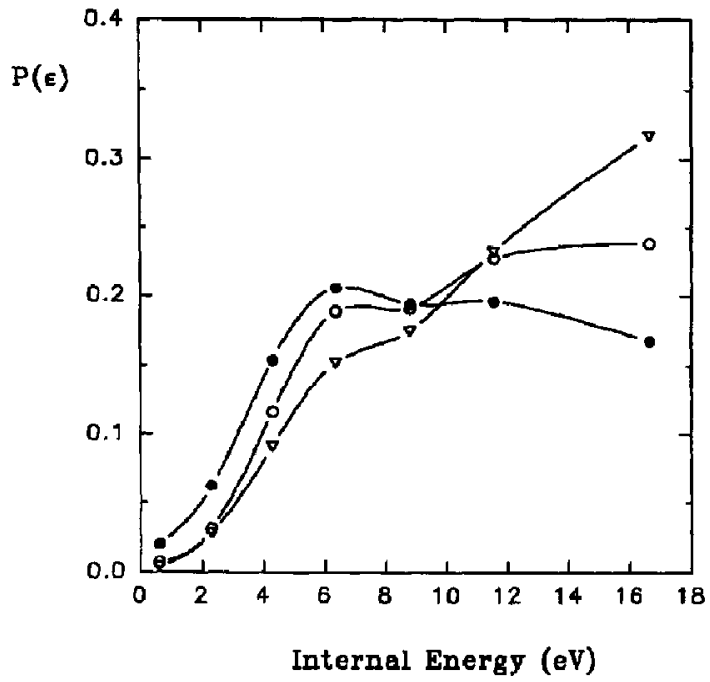

Figure 4. Internal energy distributions of $\mathrm{W}(\mathrm{CO})_{6}^{+-}$ions after $\mathrm{NR}$ at $8 \mathrm{keV}$ with trimethylamine (TMA; - ), xenon (O), and helium $(\nabla)$ for neutralization. Oxygen was the reionization target. All data are hased on peak areas.

rise in the final average internal energies acquired (by $+1 \mathrm{eV}$ from TMA to $\mathrm{Xe}$ and $+1 \mathrm{eV}$ from $\mathrm{Xe}$ to $\mathrm{He}$ ). It must be emphasized though that this growth is mainly due to the position of the last point $\left(W^{+}\right)$of the $P(\epsilon)$ curve; this point carries a relatively large weight in Figure 4 , but has a somewhat uncertain placement (vide supra). Omitting $\mathrm{W}^{+\cdot}$ from the calculation of the average internal energies gained upon NR does not affect the observed trend and leads to roughly $50 \%$ smaller rises for $\mathrm{Xe}$ and He vs. TMA.

It is believed that collisional neutralization of kiloelectronvolt ions proceeds through "glancing" encounters [33]. Whether collisional activation accompanies this process remains unclear. With endothermic collisions, conversion of kinetic to internal energy must occur in order to thermochemically enable $e^{-}$exchange. Our results seem to indicate that, at the same time, some internal energy is also deposited onto the newly formed neutral. Apparently, the degree of such collisional activation increases with the endothermicity of the neutralization step (Figure 4). The amount of internal energy gained in this step may be too small to cause spontaneous unimolecular decay of stable molecules, such as $\mathrm{W}(\mathrm{CO})_{6}$, with a measurable yield. The implications could be more severe for labile weakly bound neutrals; for these, the charge exchange reaction should be kept as close to thermoneutral as possible to ensure that they are produced below their dissociation (or isomerization) thresholds.

Excitation on reionization. All NR spectra contain recovered molecular ions (Table 3) and no broad (or composite) $\mathrm{W}(\mathrm{CO})_{5}^{+\cdot}$ peaks that would be indicative of neutral dissociation. Evidently, all three neutralization targets generate $\mathrm{W}(\mathrm{CO})_{6}$ below its dissociation limit, and the excitation imparted in the neutralization step (eq 2) must be much smaller than the bond dissociation energy $\mathrm{W}(\mathrm{CO})_{5}-\mathrm{CO}(2.0 \mathrm{eV})$. Thus, the large internal energies of $\left\{\mathrm{W}(\mathrm{CO})_{6}^{+}\right\}^{*}$ emerging from NR are mainly dispensed during reionization (eq 3 ). Assuming that TMA neutralization yields $W(\mathrm{CO})_{6}$ with some vibrational excitation, reionization with $\mathrm{O}_{2}$ (eq 3 ) leads to $\mathrm{W}(\mathrm{CO})_{6}^{+*}$ with $\leqslant 9-e V$ average activation. This value is much larger than the mean internal energy found in CAD or El, which justifies the characterization of collisional ionization as a "hard" process.

How much kinetic energy is transferred to internal energy during reinnization depends on the $e^{-}$transfer mechanism (see eq 3). If the electron is ejected, the reionizing collision supplies at least the ionization energy of $W(C O)_{6}(8.2 \mathrm{eV})$ plus the internal energy of the resulting molecular ion (mean value $\leq 9 \mathrm{eV}$ ). Overall, $\geq 17 \mathrm{eV}$ are distributed, on average, onto the tungsten hexacarbonyl molecules being cationized with $\mathrm{O}_{2}$ targets. This amount could be smaller if the removed electron is captured by $\mathrm{O}_{2}$ to form $\mathrm{O}_{2}$; , or larger if the target also receives some kind of excitation. Oxygen belongs to the "softest" reionization gases used so far. Even higher energies are possible upon reionization with other, harder targets, for example, $N_{2}$ or He [41, $60]$.

It has been shown recently by Harnish and Holmes [61] that stable molecules produced by dissociation of metastable ions decompose more extensively upon collisional ionization if they are formed rovibrationally excited. Hence, the high probability found here for depositing large internal energies on reionization, and the resulting extensive jonic fragmentation, may arise because the neutral intermediate has acquired rovibrational excitation in the neutralization step even if the latter is near thermoneutral [61]. For neutrals bound only weakly ( $<1 \mathrm{eV}$ ), this activation could be enough for (at least some) neutral dissociation [62].

Effect of kinetic energy. Reduction of the kinetic energy of $\mathrm{W}(\mathrm{CO})_{6}^{+\cdot}$ changes the $P(\epsilon)$ distribution for $\mathrm{CAD}$ (Table 2 and Figure 5). Less activated populations gain in relative weight at the smaller kinetic energies; this in turn lowers the mean value of internal energy deposited, from $<6 \mathrm{eV}$ at $8 \mathrm{keV}$ to $<5 \mathrm{eV}$ at $5 \mathrm{keV}$ and to $<4 \mathrm{eV}$ at $3 \mathrm{keV}$. Parallel effects were observed by Cooks and co-workers [48] for precursor ions accelerated to $1.5-3.0 \mathrm{keV}$.

The NR (TMA $/ \mathrm{O}_{2}$ ) spectra also are affected when the kinetic energy is decreased (Table 3). Less energydemanding products gain in abundance at the lower kinetic energy; for example, the base peak corresponds to $\mathrm{W}^{+\cdot}$ at $8 \mathrm{keV}, \mathrm{W}(\mathrm{CO})_{1-2}^{+-}$at $5 \mathrm{keV}$, and $\mathrm{W}(\mathrm{CO})_{3}^{{ }^{+}}$at 3 $\mathrm{keV}$. In the respective $P(\epsilon)$ distributions (Figure 6), the probabilities for transfer of large energy amounts recede (and vice versa) as the kinetic energy becomes smaller. Note that the curve shape is markedly different at $3 \mathrm{keV}$; it presents a well defined maxi- 


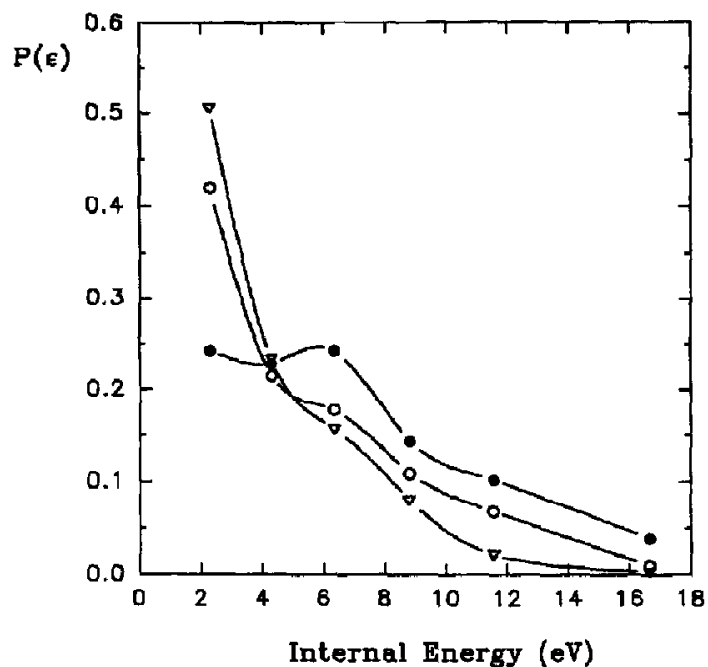

Figure 5. Internal energy distributions of $\mathrm{W}(\mathrm{CO})_{6}^{+\cdot}$ ions after $\mathrm{CAD}\left(\mathrm{O}_{2}\right)$ at $8 \mathrm{keV}(\mathrm{O}), 5 \mathrm{keV}(\mathrm{O})$, and $3 \mathrm{keV}(\nabla)$. All data are based on peak areas.

mum about $4.5 \mathrm{eV}$. The average deposited internal energy falls from 9 to 7 to $6 \mathrm{eV}$ as the kinetic energy is changed from $8 \rightarrow 5 \rightarrow 3 \mathrm{keV}$. It is worth noting that the mean internal energy of neutralizedreionized $\mathrm{W}(\mathrm{CO})_{6}^{+\cdot}$ at $3 \mathrm{keV}(6 \mathrm{eV})$ is comparable to the $z 5 \mathrm{eV}$ mean internal energy deposited upon the collision-induced dissociative ionization (CIDI) of 3$\mathrm{keV}$ acetone molecules, produced by the fragmentation $\left(\mathrm{C}_{3} \mathrm{H}_{6} \mathrm{O}\right)_{2} \mathrm{H}^{+}$(proton-bound dimer) $\rightarrow \mathrm{C}_{3} \mathrm{H}_{7} \mathrm{O}^{+}$ $+\mathrm{C}_{3} \mathrm{H}_{6} \mathrm{O}$ [41]. This similarity reinforces the fact that the internal energy of the nascent molecular ions emerging on $\mathrm{NR}$ is basically imparted during the reionization event.

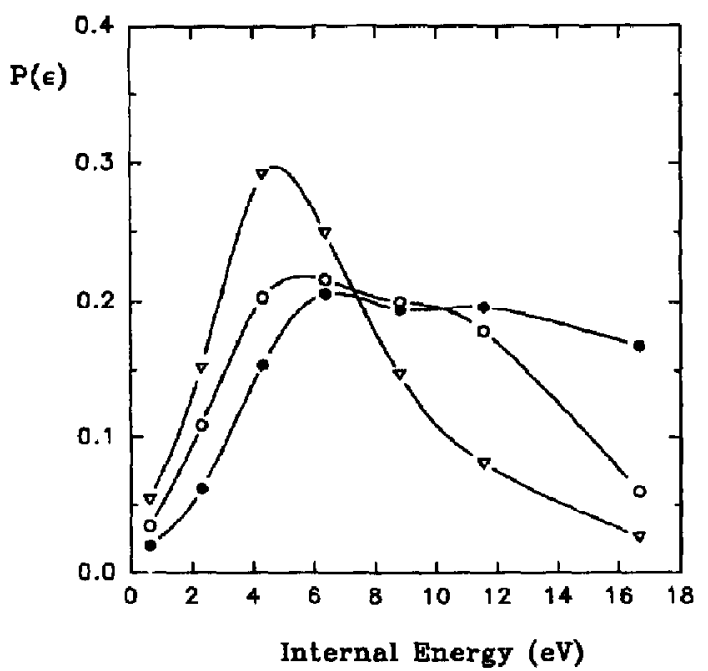

Figure 6. Internal energy distributions of $W(C O)_{6}^{+\cdot}$ ions after $\mathrm{NR}\left(\mathrm{TMA} / \mathrm{O}_{2}\right.$ ) at $8 \mathrm{keV}(\mathrm{O}), 5 \mathrm{keV}(\mathrm{O})$, and $3 \mathrm{keV}(\nabla)$. All data are based on peak areas.
Charge stripping in neutralization-reionization. A noticeable difference between CAD (or EI) and NR spectra is the very low abundance of the $W(\mathrm{CO})_{n}^{2+}$ series in the latter (see, e.g., Figure 1). Such doubly charged fragments require high critical energies [37], and high energies are more readily available through NR than through CAD or EI (vide supra). Still, $\mathrm{W}(\mathrm{CO})_{n}^{2+}$ are barely visible in the NR spectrum. This is probably due to a much poorer Franck-Condon factor for the reaction $\mathrm{W}(\mathrm{CO})_{6}$ (neutral molecule) $\rightarrow W(\mathrm{CO})_{6}^{2+}$ than for the reaction $\mathrm{W}(\mathrm{CO})_{6}^{+-}$(monocation) $\rightarrow \mathrm{W}(\mathrm{CO})_{6}^{2+}$.

\section{Conclusions}

The internal energy distributions of $\mathrm{W}(\mathrm{CO})_{6}^{+\cdot}$ ions generated upon neutralization-reionization have been compared to the internal energies gained by electron ionization or collisional activation. The $P(\epsilon)$ curves for $\mathrm{CAD}$ are characterized by a decreasing probability for the deposition of larger energies. In contrast, the distribution for NR is very broad, with a significant probability of transferring internal energies greater than 10 $\mathrm{eV}$. With near thermoneutral neutralization, the average energy deposited upon NR of $8 \mathrm{keV} \mathrm{W}(\mathrm{CO})_{6}^{+\cdot}$ is $\sim 9 \mathrm{eV}$ and primarily $(\gg 7 \mathrm{eV})$ originates in the reionization step. Endothermic charge exchange yields similar $P(\epsilon)$ distributions, with the mean internal excitation slightly increasing as the endothermicity of the neutralization step becomes larger.

The large internal energies available in NRMS experiments can be advantageous in structural analyses. Large energies usually favor direct cleavages and minimize the extent of complicating rearrangements [31, 33]. This could be the reason for the superiority of NRMS in differentiating certain isomeric ions [63].

\section{Acknowledgments}

This work was supported by the Ohio Board of Regents and the National Institutes of Health. We are grateful to Dr. Peter A. Bott and Michael I. Polce for experimental assistance.

\section{References}

1. Wesdemiotis, C.; McLafferty, F. W. Chem. Rev. 1987, 87, $485-500$.

2. Terlouw, J. K.; Schwarz, H. Angew. Chen., Int. Ed. Engl. 1987, 26, 805-815.

3. Holmes, J. L. Mass Spectrom. Rev. 1989, 8, 513-539.

4. Polce, M. J.; Wesdemiotis, C. Mass Spectrometry in the Biological Sciences; Gross, M. L., Ed.; Kluwer Academic Publishers: Dordrecht, 1992; p. 303.

5. Gellene, G. I,; Porter, R. F. Acc. Chem. Res. 1983, 16, 200-207.

6. McLafferty, F. W. Science 1991, 247, 925-929.

7. Harrrison, A. G.; Mercer, R. S.; Reiner, E. J.; Young, A. B.; Boyd, R. K.; March, R. E.; Porter, C. J. Int. J. Mass Spectrom. Ion Processes 1986, 74, 13-31.

8. Wesdemintis, C; McLafferty, F. W. J. Am. Chem. Soc. 1987, 109, 4760-4761.

9. Wesdemiotis, C.; Leyh, B; Fura, A.; McLafferty, F. W. J. Ant. Chem. Soc. 1990, 112, 8655-8660. 
10. Sülzle, D.; Drewello, T.; van Baar, B. L. M.; Schwarz, H. t. Am. Chem. Soc. 1988, 110, 8330-8333.

11. Gellene, G, I.; Porter, R. F. J. Chemi. Phys. 1984, 81, 5570-5576.

12. Wesdemiotis, C,; Feng, R.; McLafferty, F, W. J. Am. Chem. Suc. 1986, $108,5656-5657$.

13. Holmes, J. L.; Sirois, M. Org. Mass Spectrom. 1990, 25, 481-482.

14. Wesdemiotis, C.; Fura, A.; McLafferty, F. W. J. Am. Soc. Mass Spectrom. 1991, 2, 459-463.

15. Polce, M. J.; Wesdemiotis, C. J. Am. Chem. Soc. 1993, 115. $10849-10856$

16. Terlouw, J. K.; Lebrilla, C. B,; Schwarz, H. Angew, Chem., Int. Ed. Engl. 1987, 26, 354-355.

17. Van Baar, B.; Weiske, T.; Terlouw, J. K.; Schware, H. Angew, Chem, Int, Ed. Engl. 1986, 25, 282-284.

18. Wiedmann, F. A.; Wesderniotis, C. J. Am. Chem. Soc. 1994, 116, 2481-2485.

19. Burgers, P. C.; Holmes, J. L; Mommers, A. A.; Terlouw, J. K. Chem. Phys. Lett. 1983, 102, 1-3.

20. Burgers, P. C.; Holmes, J. L.; Hop, C. E. C. A.; Terlouw, J. K. Org. Mass Spectrom. 1986, 21, 549-555

21. Wesdemiotis, C.; Feng, R.; Danis, P. O.; Williams, E. R.; McLafferty, F. W. Org. Mass Spectrom. 1986, 21, 689-695.

22. Holmes, J. L.; Hop, C. E. C. A.; Terlouw, J. K. Org. Mass Spectrom. 1986, 21, 776-778.

23. Cordero, M. M.; Houser, J. J.; Wesdemiotis, C. Anal. Chem. 1993, 65, 1594-1601.

24. Cordero, M. M.; Wesdemiotis, C. Org. Mass Spectrom. 1993, 28, 1041-1046.

25. Cordero, M. M.; Wesdemiotis, C. Org. Mass Spectrom. 1994, $29,382-390$.

26. Cordero, M. M.; Wesdemiotis, C. Anal. Chern. 1994, 66, 861-866.

27. Danis, P. O.; Feng, R.; McLafferty, F. W. Anal. Chem. 1986, $58,348-355$.

28. Hop, C. E. C. A,; Holmes, J. L. Org. Mass Spectrom. 1991, 26, $476-480$.

29. Hop, C. E. C. A.; Holmes, J. L.; Wang, M. W.; Radom, L. Chem. Phys. Lett. 1989, 159, 580-586.

30. Feng, R.; Wesdemiotis, C.; Zhang, M.-Y.; Marchetti, M.; McLafferty, F. W. J. Am. Chem. Soc. 1989, 111, 1986-1991.

31. McLafferty, F. W.; Turecek, F. Interpretation of Mass Spectra, 4th ed.; University Science Books: Mill Valley, CA, 1993.

37. McLafferty, F. W. Renete, P. F., III; Komfeld, R.; Tsai, S.C.; Howe, I. I. Am. Chem. Soc. 1973, 95, 2120-2129.

33. Busch, K. I.; Glish, G. L.; McLuckey, S. A. Mass Spectrometry/Mass Spectrometry; VCH Publishers: New York, 1988.

34. Wysocki, V. H.; Kenttämaa, H. I.; Cooks, R. C. Int. I. Mass Splectrom. Ion Processes 1987, 75, 181-208.

35. Cooks, R. G., Ed. Collision Spectroscopy; Plenum: New York, 1978.

36. Vekey, K.; Brenton, A. G.; Beynon, J. H. Int. J. Mass Spectrom. Ion Processes 1986, 70, 277-300.

37. Cooks. R. G.; Ast. T.; Kralj, B.; Kramer, V.; Zigon, D. J. Am. Soc. Mass Spectrom. 1990, 1, 16-27.

38. Susic, R.; Lu, L.; Riederer, D. E., Jr.; Zigon, D.; Cooks, R. G.; Ast, T. Org. Mass Spectrom. 1992, 27, 769-776.
39. Riederer, D. E., Jr.; Lu, L.; Cooks, R. G. Org- Mass Spectrom. $1993,23,382-389$.

40. Wysucki, V. H.; Kenttämaa, H. I.; Cooks, R. G. I. Phys. Chem. 1988, $92,6465-6469$.

41. Vekey, K.; Brenton, A. G. Rapid Commun. Mass Spectrom. 1988, 2, 156-161.

42. Burgers, P. C.; Holmes, J. L.; Mommers, A. A.; Szulejko, J. E.; Terlouw, J. K. Org. Mass Spectrom. 1984, 19, 442-447.

43. Clair, R.; Holmes, ]. L.; Mommers, A. A.; Terlouw, J. K. Org. Mass Spectrom. 1985, 20, 207-212.

44. Polce, M. J.; Cordero, M. M.; Wesdemiotis, C.; Bott, P. A. Int. J. Mass Spectrom. Ion Processes 1992, 113, 35-58.

45. Holmes, J. L. Org. Mass Spectrom. 1985, 20, 169-183.

46. Li, X.; Harrison, A. G. J. Ant. Chem. Soc. 1993, 115, 6327-6332.

47. Kenttämaa, H. I.; Cooks, R. G. Int. I. Mass Spectrom. Ion Processes 1985, 64, 79-83.

48. Horning, S. R.; Vincenti, M.; Cooks, R. G. J. Am. Chem. Soc. $1990,112,119-126$.

49. Schey, K. L.; Kenttämaa, H. I.; Wysocki, V. H.; Cooks, R. G. Int. J. Mass Spectrom. Ion Processes 1989, 90, 71-83.

50. Gord, J. R.; Horning, S. R.; Wood, J. M.; Cooks, R. G.; Freiser, B. S. I. Am. Soc. Mass Spectrom. 1993, 4, 145-151.

51. (a) Cooks, R. G.; Ast, T.; Mabud, MD. A. Int. J. Mass Spectron. Ion Processes 1990, 100, 209-265; (b) Wysacki, V. H,; Ding, J.-M.; Jones, J. L.; Callahan, J. H.; King, F. L. J. Am. Soc. Mass Spectrom. 1992, 3, 27-32.

52. For convoluted kinetic energy releases from consecutive fragmentations, see: Proctor, C. J.; Kralj, B.; Brenton, A. G.; Beynon, J. H. Org. Mass Spectrom. 1980, 15, 619-631.

53. Lewis, K. E.; Golden, D. M.; Smith, G. P. J. Am. Chem. Soc. 1984, 106, 3905-3912.

54. Kimura, K.; Katsumata, S.; Achiba, Y.; Yamazaki, T.; Iwata, S. Handbook of HeI Photoelectron Spectra of Fundamental Organic Molecules; Halsted Press: New York, 1981; p 121.

55. Lias, S. G.; Bartmess, J. E.; Liebman, J. F; Holmes, J. L; Levin, R. D.; Mallard, W. G. I. Phys. Chem. Ref. Data 1988, 17, Suppl. 1.

56. Higginson, B. R.; Lloyd, D. R.; Burroughs, P.; Gibson, D. M.; Orchard, A. F. J. Chem. Soc., Faraday Trans. II 1973, 1659-1668.

57. Gellene, G. I; Williams, B. W.; Porter, R. F. I. Chem. Phys. $1981,74,5636-5642$.

58. Zhang, M.-Y.; Wesdemiotis, C.; Marchetti, M.; Danis, P. O.; Ray, J. C., Jr.; Carpenter, B. K.; McLafferty, F. W. J. Am. Chem. Soc. 1989, 111, 8341-8346.

59. IIop. C. E. C. A.; IIolmes, J. L. Int. J. Mass Spectron, Ion Processes 1991, 104, 213-226.

60. Danis, P. O.; Feng, R.; McLafferty, F. W. Anal. Chem. 1986, $58,355-358$

61. Harnish, D.; Holmes, J. L. Org. Mass Spectrom. 1994, 29, $213-219$

62. Kuhns, D. W.; Tran, T. B.; Shaffer, S. A.; Turecek, F. J. Phys. Chem. 1994, 98, 4845-4853.

63. Zhang, M.-Y.; Carpenter, B. K.; McLafferty, F. W. J. Am. Chem. Soc. 1991, 113, 9499-9503. 